\title{
Analysis of Sorption into Single ODS-Silica Gel Microparticles in Acetonitrile-Water
}

\author{
Kiyoharu NaKaTANI ${ }^{\dagger}$ and Hiroshi KaKIZAKI \\ Department of Chemistry, University of Tsukuba, 1-1-1 Tennoudai, Tsukuba 305-8571, Japan
}

\begin{abstract}
Intraparticle mass transfer processes of Phenol Blue (PB) in single octadecylsilyl (ODS)-silica gel microparticles in acetonitrile-water were analyzed by microcapillary manipulation and microabsorption methods. An absorption maximum of $\mathrm{PB}$, the sorption isotherm parameters, and the sorption rate in the microparticle system were highly dependent on the percentage of acetonitrile in solution. The results are discussed in terms of the microscopic polarity surrounding PB in the ODS phase and the relationship between the isotherm parameters and the sorption rate.
\end{abstract}

(Received April 28, 2003; Accepted June 6, 2003)

\section{Introduction}

Studies of the sorption and desorption processes in microparticle systems are significant for understanding the microscopic mechanisms of solid-phase extraction, liquid chromatography, mass transport in soil, and so forth. ${ }^{1-8}$ Because the sorption and desorption processes of a solute in octadecylsilyl (ODS)-silica gel systems are highly dependent on the volume ratio of an organic solvent to water in a mixture solvent, measurements of the microscopic polarity of an ODS phase are necessary for analyses of the separation processes. In liquid chromatography, a solute in a mobile phase distributes into an ODS phase, dependent on the flow rate of the mobile phase, the adsorption/desorption rates, the intraparticle diffusion rate, and so on. Therefore, direct measurements of the sorption rates in ODS-silica gel systems are indispensable for analyzing the separation mechanism. In this article, the sorption of Phenol Blue (PB), known as a solvatochromic dye, ${ }^{9}$ into single ODSsilica gel microparticles in acetonitrile-water was analyzed using microcapillary manipulation and microabsorption methods, by which a single microparticle can be injected into a solution and the absorption spectrum of the single microparticle is measured with time..$^{10,11}$ We discuss the microscopic polarity in the ODS-silica gel system and diffusion of PB in the pores of the microparticles.

\section{Experimental}

After spherical ODS-silica gel (Wako Pure Chemical, Wakosil 40C18: particle diameter $(d), 20-60 \mu \mathrm{m}$; surface area, 330 $\mathrm{cm}^{2} / \mathrm{g}$; pore diameter $\left(d_{\mathrm{p}}\right), 12 \mathrm{~nm}$; pore volume $\left.\left(V_{\mathrm{p}}\right), 1.0 \mathrm{~cm}^{3} / \mathrm{g}\right)$ was soaked in acetonitrile, the solvent was repeatedly replaced with acetonitrile-water (percentage by volume of acetonitrile, $0-15 \mathrm{vol} \%)$ containing $\mathrm{KCl}\left(0.01 \mathrm{~mol} / \mathrm{dm}^{3}\right)$. Single microparticle measurements were performed at $298 \pm 0.5 \mathrm{~K}$ by microcapillary manipulation and microabsorption methods (Fig.

† To whom correspondence should be addressed.

E-mail: nakatani@chem.tsukuba.ac.jp
1). ${ }^{10,11}$ A single ODS-silica gel in a $\mathrm{KCl} /$ acetonitrile-water solution was sucked into a microcapillary and injected into a $\mathrm{KCl}\left(0.01 \mathrm{~mol} / \mathrm{dm}^{3}\right) /$ acetonitrile-water solution containing PB using the microcapillary manipulation method. The time dependence of the absorption spectrum for a single microparticle was measured by the microabsorption method.

\section{Results and Discussion}

Figure 2 shows the absorption spectra of PB sorbed into single ODS-silica gel microparticles for 0 and $15 \mathrm{vol} \%$ of acetonitrile. The absorbance of PB increased with time and became saturated. Both the ratio of a saturated absorbance value $\left(A_{\text {eq }}\right)$ to the $\mathrm{PB}$ concentration in an acetonitrile-water solution $\left(C_{\mathrm{a}-\mathrm{w}}\right)$ and the time to saturation significantly increased with the decreasing percentage of acetonitrile. The absorption spectrum of PB is highly dependent on the solvent polarity and hydrogen bonding. ${ }^{9}$ In water, acetonitrile (20 vol\%)-water, methanol, or acetonitrile, the absorption maximum of $\mathrm{PB}\left(\lambda_{\max }\right)$ was

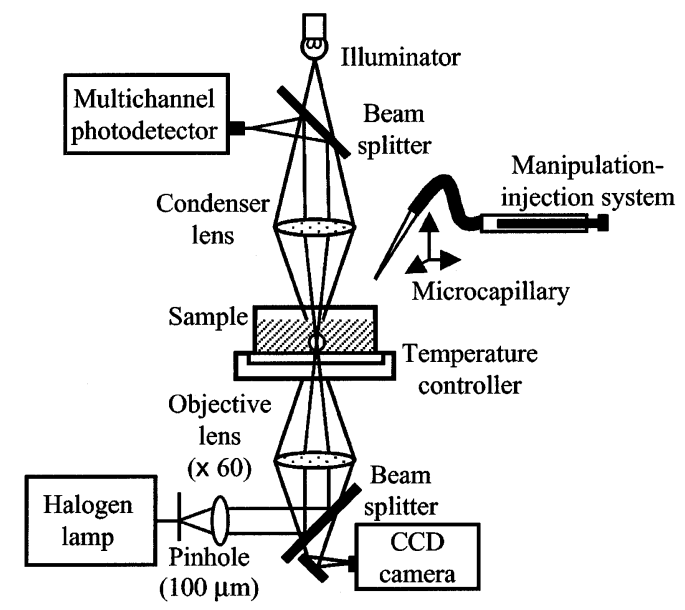

Fig. 1 Block diagram of microcapillary manipulation and microabsorption methods. 




Fig. 2 Absorption spectra of $\mathrm{PB}$ in single ODS-silica gel microparticles for (a) $0 \mathrm{vol} \%\left(C_{\mathrm{a}-\mathrm{w}}=3 \times 10^{-7} \mathrm{~mol} / \mathrm{dm}^{3}, d=45 \mu \mathrm{m}\right)$ and (b) $15 \mathrm{vol} \%$ of acetonitrile $\left(C_{\mathrm{a}-\mathrm{w}}=2 \times 10^{-5} \mathrm{~mol} / \mathrm{dm}^{3}, d=48 \mu \mathrm{m}\right)$.

determined to be $658,648,609$, or $583 \mathrm{~nm}$, respectively. In the ODS-silica gel system, $\lambda_{\max }$ in the single microparticle was 626 , 615,612 , or $609 \mathrm{~nm}$ for $0,5,10$, or $15 \mathrm{vol} \%$ of acetonitrile, respectively. $\lambda_{\max }$ in the microparticle for $0 \mathrm{vol} \%$ of acetonitrile $(626 \mathrm{~nm})$ is much smaller than that in water $(658 \mathrm{~nm})$. The microscopic polarity surrounding $\mathrm{PB}$ is low due to the distribution of PB into the ODS phase. However, $\lambda_{\max }$ in the microparticle is greater than that in acetonitrile $(583 \mathrm{~nm})$. Therefore, PB will be located in the vicinity of the ODS/solution interface and be partially solvated by solvent molecules.

Figure 3 shows the time dependence of the PB absorbance $(A(t))$ for $0 \mathrm{vol} \%$ of acetonitrile in the microparticle system. $A_{\mathrm{eq}}$ was directly proportional to $d$. A probe beam $(2 \mu \mathrm{m}$ spot size $)$ from the halogen lamp was passed through the particle center during the microabsorption method (Fig. 1). ${ }^{11}$ If PB is adsorbed only on the particle surface, $A_{\mathrm{eq}}$ is independent of $d$, as previously reported. ${ }^{12}$ This result indicates that water molecules enter the pores having hydrophobic walls in the ODS-silica gel, and $\mathrm{PB}$ is sorbed into the particle interior. The $\mathrm{PB}$ concentration in the microparticle at sorption equilibrium $\left(C_{\mathrm{p}, \mathrm{eq}}\right)$ was determined using Lambert-Beer's law, $A_{\mathrm{eq}}=\varepsilon d C_{\mathrm{p}, \mathrm{eq}}$, where $\varepsilon$ is the molar extinction coefficient of $\mathrm{PB}$ at the peak wavelength. Because the respective $\varepsilon$ values in water and acetonitrile were $2.0 \times 10^{4}$ and $2.1 \times 10^{4} \mathrm{~mol}^{-1} \mathrm{dm}^{3} \mathrm{~cm}^{-1}, \varepsilon$ in the microparticle was assumed to be equal to be $2.0 \times 10^{4} \mathrm{~mol}^{-1} \mathrm{dm}^{3}$ $\mathrm{cm}^{-1}$. We analyzed $C_{\mathrm{p}, \mathrm{eq}}$ and $C_{\mathrm{a}-\mathrm{w}}$ using the Langmuir isotherm, $C_{\mathrm{p}, \mathrm{eq}}=K_{\mathrm{L}} C_{\mathrm{p}, \infty} C_{\mathrm{a}-\mathrm{w}} /\left(1+K_{\mathrm{L}} C_{\mathrm{a}-\mathrm{w}}\right)$, where $K_{\mathrm{L}}$ and $C_{\mathrm{p}, \infty}$ are the Langmuir isotherm constant and the Langmuir constant, respectively. $C_{\mathrm{a}-\mathrm{w}}$ at the sorption equilibrium was assumed to be equal to that at the sample preparation because the volume of the solution phase $\left(3 \mathrm{~cm}^{3}\right)$ was much greater than that of a single microparticle $\left(1.4 \times 10^{-8} \mathrm{~cm}^{3}\right.$ for $\left.d=30 \mu \mathrm{m}\right) . \quad K_{\mathrm{L}}$ drastically changed with the percentage of acetonitrile $\left(5.3 \times 10^{5}(0 \mathrm{vol} \%)\right.$, $2.0 \times 10^{5}(5 \mathrm{vol} \%), 1.2 \times 10^{4}(10 \mathrm{vol} \%), 9.3 \times 10^{3} \mathrm{~mol}^{-1} \mathrm{dm}^{3}(15$ vol\%)), while $C_{\mathrm{p}, \infty}$ was almost constant $\left((5 \pm 2) \times 10^{-2} \mathrm{~mol} / \mathrm{dm}^{3}\right)$.

External mass transfer from a bulk solution phase to a single microparticle surface (spherical diffusion) is much faster than the intraparticle mass transfer, as reported in single silica gel microparticle systems. ${ }^{10}$ Therefore, sorption into single microparticles can be analyzed using an intraparticle diffusion

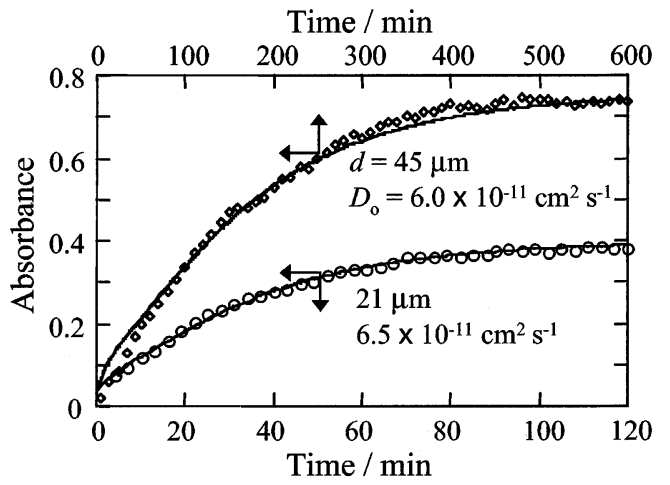

Fig. 3 Time dependence of the peak absorbance of PB in single ODS-silica gel microparticles with $d=45$ and $21 \mu \mathrm{m}$ for 0 vol\% of acetonitrile at $C_{\mathrm{a}-\mathrm{w}}=3 \times 10^{-7} \mathrm{~mol} / \mathrm{dm}^{3}$. The solid curves represent the simulations of $A(t)$

model. For a spherical particle, the time dependence of the radial concentration profile of a solute in the particle $\left(C_{\mathrm{p}}(r, t)\right)$ is given by the equation $\partial C_{\mathrm{p}}(r, t) / \partial t=D_{\mathrm{o}}\left\{\partial^{2} C_{\mathrm{p}}(r, t) / \partial r^{2}+\right.$ $\left.(2 / r) \partial C_{\mathrm{p}}(r, t) / \partial r\right\}$, where $D_{\mathrm{o}}$ and $r$ are the apparent diffusion coefficient of the solute in the particle interior and the radially directed spatial coordinate, respectively. ${ }^{11,13}$ Under the conditions $C_{\mathrm{p}}(r, 0)=0, C_{\mathrm{p}}(d / 2, t)=C_{\mathrm{p} \text {,eq }}$ and $\partial C_{\mathrm{p}}(0, t) / \partial r=0, A(t)$ $\left(=2 \varepsilon \int_{0}^{\mathrm{d} / 2} C_{\mathrm{p}}(r, t) d r\right)$ was simulated for various $D_{\mathrm{o}}$ values. The simulated $A(t)$ curves of single microparticles for $0 \mathrm{vol} \%$ of acetonitrile are shown in Fig. 3. The $D_{\mathrm{o}}$ value was independent of $C_{\mathrm{a}-\mathrm{w}}$ and $d$ for the same percentage of acetonitrile, while $D_{\mathrm{o}}$ increased with the increasing percentage of acetonitrile.

Intraparticle diffusion processes consist of diffusion in a solution phase of pores (pore diffusion) and that at the interface of the pore walls (surface diffusion). The contribution of the surface diffusion to $D_{\mathrm{o}}$ is generally assumed to be negligibly small in silica gel systems. In this case, $D_{0}$ is given by the equation $D_{\mathrm{o}}=D_{\mathrm{a}-\mathrm{w}} H\left(a, d_{\mathrm{p}}\right) / \tau\left(1+K_{\mathrm{c}}\right),{ }^{14}$ where $D_{\mathrm{a}-\mathrm{w}}$ and $\tau$ are the diffusion coefficient of PB in the acetonitrile-water phase and the tortuosity of the ODS-silica gel $(1.5),{ }^{15}$ respectively. $K_{\mathrm{c}}$ is the distribution coefficient, defined by the ratio of the $\mathrm{PB}$ concentration in the ODS phase at the pore wall $\left(C_{\mathrm{p}, \mathrm{ODS}}\right)$ to that in the solution phase in the pores $\left(C_{\mathrm{p}, \mathrm{a}-\mathrm{w}}\right)$, and is obtained by $K_{\mathrm{L}} C_{\mathrm{p}, \infty} / \varepsilon_{\mathrm{p}}-1$ because of $C_{\mathrm{p}, \mathrm{eq}}=C_{\mathrm{p}, \mathrm{ODS}}+C_{\mathrm{p}, \mathrm{a}-\mathrm{w}}$ and $C_{\mathrm{a}-\mathrm{w}}=C_{\mathrm{p}, \mathrm{a}-\mathrm{w}} / \varepsilon_{\mathrm{p}}$ ( $\varepsilon_{\mathrm{p}}$ : porosity, 0.69). ${ }^{15} H\left(a, d_{\mathrm{p}}\right)$ is the hindrance parameter, dependent on the diameter of PB $(a=1 \mathrm{~nm})$ and $d_{\mathrm{p}}(12 \mathrm{~nm})$, and is estimated to be 0.69 using the Renkin equation: $H\left(a, d_{\mathrm{p}}\right)=(1-$ $\left.a / d_{\mathrm{p}}\right)^{2}\left\{1-2.10\left(a / d_{\mathrm{p}}\right)+2.09\left(a / d_{\mathrm{p}}\right)^{3}-0.95\left(a / d_{\mathrm{p}}\right)^{5}\right\} .{ }^{16}$ Figure 4 shows the $K_{\mathrm{c}}$ dependence of $D_{\mathrm{o}}$. A theoretical curve simulates the data at $D_{\text {a-w }}=6 \times 10^{-6} \mathrm{~cm}^{2} / \mathrm{s}$, which is close to the typical diffusion coefficient of a solute in water. This result indicates that the sorption of PB into the ODS-silica gel can be successfully analyzed by the present theoretical pore diffusion model.

\section{Conclusions}

The sorption of PB into ODS-silica gel was sufficiently analyzed by single microparticle measurements. We showed that PB adsorbs at the ODS/solution interface in the pores. Although the pore walls are hydrophobic, water, acetonitrile and PB molecules could enter the particle interior in the ODS-silica gel. The Langmuir isotherm parameters and $D_{0}$ were highly dependent on the percentage of acetonitrile in solution. On the 


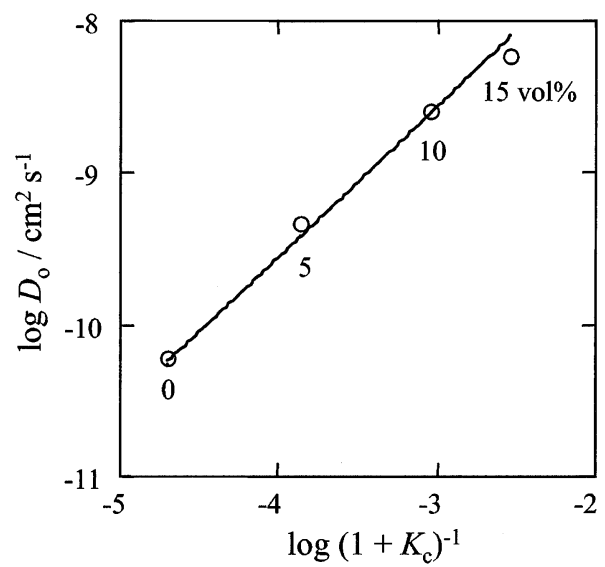

Fig. 4 Relationship between the distribution coefficient $\left(K_{\mathrm{c}}\right)$ and the apparent diffusion coefficient $\left(D_{\mathrm{o}}\right)$ for $0-15 \mathrm{vol} \%$ of acetonitrile. The solid curve represents the calculation of $D_{\mathrm{o}}$ using $H\left(a, d_{\mathrm{p}}\right)=0.69$, $\tau=1.5$ and $D_{\text {a-w }}=6 \times 10^{-6} \mathrm{~cm}^{2} / \mathrm{s}$.

other hand, the relationship between the isotherm parameters and $D_{\mathrm{o}}$ could be analyzed on the basis of the pore diffusion model, independent of the percentage of acetonitrile. We consider that valuable information on microparticles for solidphase extraction and liquid chromatography can be obtained using the present technique.

\section{References}

1. H.-B. Kim, M. Hayashi, K. Nakatani, N. Kitamura, K. Sasaki, J. Hotta, and H. Masuhara, Anal. Chem., 1996, 68, 409.

2. H.-B. Kim, S. Habuchi, M. Hayashi, and N. Kitamura, Anal. Chem., 1998, 70, 105.

3. H. Liu and F. F. Cantwell, Anal. Chem., 1991, 63, 993.

4. N. Felitsyn and F. F. Cantwell, Anal. Chem., 1999, 71, 1862.

5. C. J. Werth and M. Reinhard, Environ. Sci. Technol., 1997, $31,697$.

6. J. Farrell, D. Grassian, and M. Jones, Environ. Sci. Technol., 1999, 33, 1237.

7. J. J. Pignatello and B. Xing, Environ. Sci. Technol., 1995, 30,1 .

8. T. Sekine and K. Nakatani, Langmuir, 2002, 18, 694.

9. J. Figueras, J. Am. Chem. Soc., 1971, 93, 3255.

10. K. Nakatani and T. Sekine, J. Colloid Interface Sci., 2000, $225,251$.

11. K. Nakatani and T. Sekine, Langmuir, 2000, 16, 9256.

12. N. Kitamura, M. Hayashi, H.-B. Kim, and K. Nakatani, Anal. Sci., 1996, 12, 49 .

13. A. P. Mathews and W. J. Weber Jr., AIChE Symp. Ser., 1976, 73, 91 .

14. J. Li and F. F. Cantwell, J. Chromatogr. A, 1996, 726, 37.

15. R. Bujalski and F. F. Cantwell, Langmuir, 2001, 17, 7710.

16. W. M. Deen, AIChE J, 1987, 33, 1409. 